\title{
Correction Models of Pneumonia Mortality Rates in the Elderly in Brazil from 2005 to 2016
}

\author{
Denismar Borges de Miranda ${ }^{1 *}$, Gabriela Moreira Policena ${ }^{2}$, Ruth Minamisava ${ }^{3}$, Ana Luiza \\ Bierrenbach $^{4}$, Ana Lúcia Andrade ${ }^{5}$ and Otaliba Libânio de Morais Neto ${ }^{6}$ \\ ${ }^{1}$ PhD in Tropical Medicine and Public Health from the Institute of Tropical Pathology and Public Health at the Federal University \\ of Goiás. Physician at the Municipal Health Department of Goiânia, Goiás, Brazil
}

${ }^{2}$ PhD student in Tropical Medicine and Public Health from the Institute of Tropical Pathology and Public Health at the Federal University of Goiás, Brazil

${ }^{3}$ PhD in Tropical Medicine and Public Health from the Institute of Tropical Pathology and Public Health at the Federal University of Goiás. Full professor at the Federal University of Goiás, Goiânia, Brazil

${ }^{4} \mathrm{PhD}$ in Infectious Disease Epidemiology by the University of London. Free teaching by the Institute of Tropical Medicine, University of São Paulo. Consultant and adviser in the field of epidemiology and scientific research and acts as a researcher and advisor for the graduate program at the Teaching and Research Institute of Hospital Sírio-Libanês and Federal University of Goiás, Brazil

${ }^{5}$ PhD in epidemiology from the Faculty of Public Health, University of São Paulo. Retired full professor at the Institute of Tropical Pathology and Public Health at the Federal University of Goiás. Member of the Technical Advisory Committee on Immunizations of the Ministry of Health, Researcher at the Institute for the Evaluation of Health Technology, Brazil

${ }^{6} \mathrm{PhD}$ in Public Health from the State University of Campinas. Associate Professor, Department of Collective Health, Federal University of Goiás, Goiânia, Goiás, Brazil

*Corresponding author: Denismar Borges de Miranda, PhD in Tropical Medicine and Public Health from the Institute of Tropical Pathology and Public Health at the Federal University of Goiás. Physician at the Municipal Health Department of Goiânia, Goiás, Brazil

\section{ARTICLE INFO}

Received: 蔧 August 07, 2020

Published: 幽 August 20, 2020

Citation: Denismar Borges de M, Gabriela Moreira P, Ruth M, Ana Luiza B and Ana Lúcia A, et al., Correction Models of Pneumonia Mortality Rates in the Elderly in Brazil from 2005 to 2016. Biomed J Sci \& Tech Res 29(4)-2020. BJSTR. MS.ID.004830.

\section{ABSTRACT}

Objective: To estimate the burden of pneumonia (PNM) mortality in the elderly in Brazil using different methodologies for rate correction.

Method: A time-series study of mortality rates from PNM in the elderly from 20052016. For the correction of the rates, two strategies were used: 1-correction by active search (CBA) and 2-correction by active search more redistribution (CBAR). In addition, a methodology for comparing corrected rates, calculated lower respiratory tract infection rates (ITRi) using estimates from the Global Burden Disease study. Trend was assessed using regression models.

Result: From 2005 to 2016, 546,068 deaths were registered, which, after using the CBAR correction strategy, left 501,380 , a reduction of $8.2 \%$. There was an increasing trend of PNM mortality rates for all regions of Brazil and for the elderly population. The largest linear increase in mortality rate due to CBAR pneumonia was observed in the Northeast.

Conclusion: These estimates of the magnitude and trend presented make it possible to analyze the behavior of mortality rates due to pneumonia in the elderly in Brazil and to subsidize the National Immunization Program on the need to include a specific pneumococcal vaccine for the entire elderly population. 
Keywords: Mortality Registries; Mortality Systems Integration; Under Registration; Pneumonia; Aged

Abbreviations: CBA: Correction by Active Search; CBAR: Correction by Active Search Plus Redistribution; DO: Death Certificate; GBD: Global Burden of Diseases Project; GC: Garbage Codes; IBGE: Brazilian Institute of Geography and Statistics; ICD-10: 10th edition of the International Statistical Classification of Diseases and Related Health Problems; IHME: Institute of Metrics and Assessment in University of Washington Health in Seattle; ITRi: Lower Respiratory Tract Infection; MS: Ministry of Health; PNM: Pneumonia; SC: Without Correction; SIH: Hospital Information System; SIM-SUS: Mortality Information System of the Unified Health System; SIM: Mortality Information System; SUS: Unified Health System; UF: Federation Units

\section{Introduction}

Since the beginning of the use of mortality data, which occurred in England in the middle of the 16th century, the information has enabled the construction of indicators that can characterize the epidemiological profile of a population. Fact that contribute to monitor health conditions and support the implementation of public health interventions targeted at a specific population. In Brazil, the Mortality Information System (SIM), implemented in 1975, has accumulated, over time, improvements in its performance, both in increasing its coverage and in the quality of information on the cause of death [1-3]. This improvement is possible due to the efforts made by SIM managers at different levels of performance. However, this work has a high cost and requires qualified professionals [4]. It is observed that there are still quality problems in the registration of the basic cause of death in the Death Certificate (DO), with high percentages of little useful codes (garbage codes - GC), registered as the basic cause of death [5]. These GC are contained in the various chapters of the 10th edition of the International Statistical Classification of Diseases and Related Health Problems (ICD-10) [6].

In addition, another problem is the lack of completeness of the information in variables present in the DO. Common examples of incorrect completion of the DO are statement not of the underlying cause but of its consequence; or just the commitment of a specific organ or system; or even the generic name of the disease, without the necessary specifications, among other examples [4,7]. Some strategies were implemented by the Ministry of Health (MS) in order to reduce the underreporting of deaths in the SIM and improve the quality of filling in the cause of death. The following stand out:

a) The research "Active Search for Deaths and Births" [8], whose purpose was to assess the underreporting of deaths in the SIM;

b) The project to reduce ill-defined causes (chapter XVIII of ICD-10);

c) The project to reduce the less useful GC codes $[8,9]$, linking mortality data with the hospitalization information system; and

d) Implantation of verbal autopsy forms for deaths without medical assistance.

These initiatives have been successful in terms of improving SIM coverage and also in the significant reduction of GC in chapter XVIII of ICD-10, but the challenge of reducing the other CG in the other chapters of ICD-10 remains, especially the causes not specified within the chapters. Currently, an intervention project is underway with medical professionals in large hospitals in the metropolitan regions of the country with the aim of qualifying the completion of the DO, in order to reduce the percentage of GC [2].

Advances in the SIM computerized system, together with improved coverage and quality of information, have enabled the development of research using its databases. The use of linkage between databases is a good example of this evolution. This technique allows to qualify the data of the information system when relating the same individual to another information system, such as, for example, the Hospital Information System (SIH), which is responsible for processing and registering all hospital admissions financed by the Unified Health System in Brazil (SUS) $[4,10,11]$. A recent study that used the linkage strategy between these two databases made it possible to identify the hospital admission diagnoses in the SIH of individuals with pneumonia (PNM) as the cause of death in the SIM. The result of the study made it possible to reclassify $17.4 \%$ of the causes in which the PNM was considered a basic cause in the SIM to other causes of death [10]. However, even with the adoption of these strategies, it is possible that the true burden of PNM in Brazil is still unknown. Based on these limitations, this research aimed to estimate the burden of mortality due to PNM in the elderly in Brazil using different rate correction methodologies.

\section{Materials and Methods}

Ecological study of time series based on the death records of 
the Mortality Information System of the Unified Health System (SIM-SUS) in Brazil, between the years 2005 and 2016. All deaths occurred in the elderly aged 60 years or older were selected age and who had, as a basic cause, PNM (ICD-10: J12-J18). Estimates of the resident population by regions of Brazil (Central-west, Northeast, North, Southeast and South), according to age group (60-64, 6579 and 80 years or older) in the study period (2005-2016) were obtained through exponential interpolation of the population of the 2000 and 2010 censuses, for the first of July, released by the
Brazilian Institute of Geography and Statistics (IBGE). The 2000 and 2010 census estimates available on the IBGE online platform were considered [12]. Mortality rates for PNM without correction (SC) per 100 thousand inhabitants were calculated using the number of deaths registered in the SIM as a numerator and the resident population for the same region, age group and period, as the denominator. To correct the rates, two strategies were used: 1-correction by active search (CBA) and 2-correction by active search plus redistribution (CBAR).

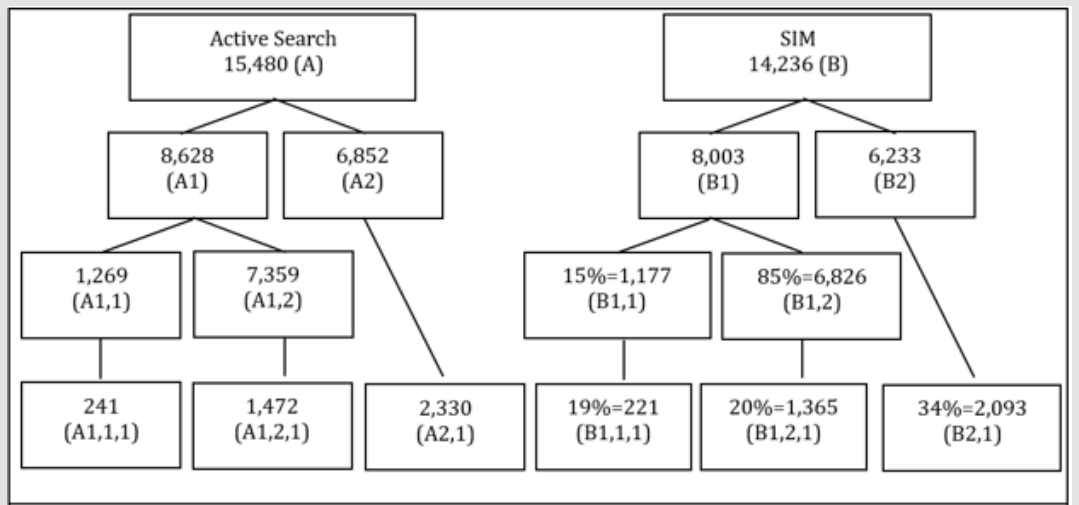

Figure 1: Example of the strategy used to calculate the CBA factor for pneumonia in 60 years or older in the South in 2005.

A: Number of deaths of Chapter X (ICD-10) of Active Search with 60 years or older

A1: Number of deaths of Chapter X (ICD-10) of the Active Search from 60 to 79 years

A2: Number of deaths in Chapter X (ICD-10) of Active Search with 80 years or older

$\mathrm{A} 1,1=\mathrm{A} 1 * \mathrm{~B} 1,1$ : Estimated number of deaths in Chapter X (ICD-10) of Active Search from 60 to 64 years

$\mathrm{A} 1,1,1=\mathrm{A} 1,1^{*} \mathrm{~B} 1,1,1$ : Estimated number of deaths from active search pneumonia from 60 to 64 years

$\mathrm{A} 1,2=\mathrm{A} 1 * \mathrm{~B} 1,2$ : Estimated number of deaths in Chapter $\mathrm{X}$ (ICD-10) of Active Search from 65 to 79 years

$\mathrm{A} 1,2,1=\mathrm{A} 1,2 * \mathrm{~B} 1,2,1$ : Estimated number of deaths from active search pneumonia from 65 to 79 years

$\mathrm{A} 2,1=\mathrm{A} 2 * \mathrm{~B} 2,1$ : Estimated number of deaths from active search pneumonia aged 80 and over

B: Number of deaths in Chapter X (ICD-10) registered in SIM aged 60 years or older

B1: Number of deaths in Chapter X (ICD-10) registered in the SIM from 60 to 79 years

B2: Number of deaths in Chapter X (ICD-10) registered in SIM aged 80 years or older

B1,1: Proportion of deaths in Chapter X (ICD-10) registered in SIM from 60 to 64 years

B1,1,1 = Proportion of deaths from pneumonia registered in the SIM from 60 to 64 years

B1,2: Proportion of deaths in Chapter X (ICD-10) registered in the SIM from 65 to 79 years

B1,2,1: Proportion of deaths due to pneumonia registered in the SIM from 65 to 79 years

B2,1: Proportion of deaths due to pneumonia registered in SIM aged 80 years or older

CBA factor 60 to 64 years $=\mathrm{A} 1,1,1 / \mathrm{B} 1,1,1=1.08$

CBA factor 65 to 79 years $=\mathrm{A} 1,2,1 / \mathrm{B} 1,2,1=1.08$

CBA factor 80 years or older $=\mathrm{A} 2,1 / \mathrm{B} 2,1=1.10$.

In the construction of the first strategy, CBA, the number of deaths underreported by PNM was estimated for the age groups of the study. In calculating the number of deaths by age group 6064 years and 65-79 years, a proportion based on the age group 60-79 years of the active search research was used [8]. The same condition was adopted for the proportion of PNM (ICD-10: J12-J18) underreported in relation to deaths from diseases of the respiratory system (chapter X - ICD-10). These estimates were based on the number of deaths reported in the SIM. From the estimate of the number of deaths underreported by PNM for the period (2005 to 2013), by age group (60-64 years, 65-79 years and 80 years or older) by regions of Brazil, it was possible to calculate the risk factor CBA for the years 2005 to 2013. Figure 1 exemplifies this strategy carried out for the South region in 2005. In a complementary way, 
the linear regression model was adopted to project the CBA factor from 2014 to 2016. This annual correction was applied to the SC rates.

The second strategy, which is a correction factor for PNM mortality data recorded in SIM, was carried out based on the results of the study on the redistribution of the basic cause of death using data matching between SIM and SIH-SUS from 2008 to 2013 [10]. The ICD-10 codes registered in the primary diagnosis field (or secondary diagnosis, only in the case of external causes) of the AIH were used to review the basic cause of death, taking into account the diagnoses of hospitalization SIH other than PNM. For this redefinition of the basic cause of death, the diagnosis of hospitalization was inserted in lines A, B, C and D of part I of the DO, where the causes that led to death are recorded, preserving the causes registered in the original DO. After inserting the diagnosis of hospitalization in the DO, the basic cause was redefined using the SIM Basic Cause Selector software. After this process, the PNM correction factor was defined as the basic cause of death for the years 2008 to 2013. The linear regression model was performed to estimate the correction factor for the other years: 2005 to 2007 and 2014 to 2016. This second correction strategy was called CBAR.

In defining the estimated mortality rate, deaths corrected by the two strategies described above, active search and active search plus the redistribution of the underlying cause, were used as numerators. Additionally, as a reference or parameter for the mortality rates estimated by the study, we used the estimates of deaths due to lower respiratory tract infection (ITRi) produced by the Global Burden of Diseases Project (GBD), from the Institute of Metrics and Assessment in University of Washington Health in Seattle (IHME). In defining this new mortality rate in the elderly, the deaths estimated by GBD were used as a numerator in the group of causes of death due to ITRi using the estimates of the GBD study [13]. The estimate by brazilian regions was possible due to the cooperation agreement between the MS of Brazil and the IHME for the production of the GBD indicators for the Federation Units (UF). GBD methodological details are available in other publications of the group, which updates its procedures and concepts since the first publication [14].

As GBD's estimates of the number of deaths by ITRi (ICD-10: A48,1, A70, J09-J15,8, J16-J16,9, J20-J21,9 and P23,0-P23,4) are available on the IHME online page by UF in Brazil, by year and by age group, the number of deaths by region was calculated from the sum of the UF [15]. Thus, the GBD mortality rate was calculated by adopting, as a numerator, the death estimate by ITRi; and, as a denominator, the same population previously described, by region, age group and year. For the analysis of the trend of mortality due to SC pneumonia, CBA, CBAR and ITRi-GBD, dispersion diagrams between the coefficients and the years of study were made in order to visualize the function that could be expressing a relationship between them. From this relationship, it was possible to choose the simple linear regression model $(Y=\beta 0+\beta 1 X)$, which, in addition to its statistical power, allows to define a forecast function [16]. In this model, $\beta 0$ is the average annual coefficient and $\beta 1$ is the coefficient of linear effect (speed). For modeling, the mortality coefficients were considered as a dependent variable (Y axis) and the years of the study series as an independent variable (X axis).

For the adjustments of these models, classic assumptions were verified, such as normality, independence and homoscedasticity of the residues [16]. The Durbin-Watson test was used to observe the autocorrelation between the residues. It was adopted as a measure of precision of the model the use of the coefficient of determination (R2). A significant trend was considered as one whose estimated model obtained a significant regression coefficient $(p<0.05)$. The study was carried out in compliance with the ethical precepts of Resolution 466, of December 12, 2012 [17], and, after its approval by the Research Ethics Committee of the Federal University of Goiás - whose number is 162,532 . Due to the fact that the use of data from a large national database is foreseen without the identification of the research subjects, there was no need to use the Informed Consent Form.

\section{Results}

In the period from 2005 to 2016, 546,056 deaths in the elderly were registered in the SIM in Brazil, with the primary cause of PNM. After applying the correction factor (CBAR), 501,380 records were considered as PNM, which corresponds to an $8.2 \%$ reduction in deaths with PNM registration as the basic cause in the period. Table 1 and Figures 2-4 show mortality rates due to PNM in the elderly without correction and those corrected during the study series. Differences were found between the adopted methodologies. The temporal evolution of mortality rates by PNM CBAR showed an increasing trend for all geographic regions of Brazil and age group in the period between 2005 and 2016 (Tables 1), (Figures $2-4)$. These also show mortality rates from ITRi-GBD with regional variations. There is a progressive increase in mortality rates due to PNM with advancing age, with higher risks in the age group of 80 years or older.

In 2016, the Southeast region had the highest mortality rate by PNM $(1,245.55 / 100,000$ inhab.), Followed by the North (1,074.09/100,000 inhab.), Central-west (965.35/100,000 inhab.), Northeast (943.64/100,000 inhab.) and South (881.96/100,000 inhab.). Figures 2-4 present the results in graph form. The number of deaths from PNM without correction, from different correction strategies and from ITRi by GBD are shown in Table 2. The linear regression model Table 3. shows an increase in the linear component (B1) for all age groups, the longer the age group, the greater the magnitude of the annual increase. The Northeast region showed the largest linear increase in the mortality rate due to CBAR pneumonia for the age groups 60-64, 65-79 and 80 years or older. 
The smallest linear increase was observed in the Central-west and years or older for the South region.

South regions, in the age group 60-64 years, and in the age group 80

Table 1: Annual rates (per 100,000) uncorrected and corrected for pneumonia mortality and ITRi by GBD by age group, region and year. Brazil, 2005-2016.

\begin{tabular}{|c|c|c|c|c|c|c|c|c|c|c|c|c|c|}
\hline \multirow{4}{*}{ Region } & \multirow{4}{*}{ Year } & \multicolumn{12}{|c|}{ Age Group (Years) } \\
\hline & & \multicolumn{4}{|c|}{$60-64$} & \multicolumn{4}{|c|}{$65-79$} & \multicolumn{4}{|c|}{$\geq 80$} \\
\hline & & \multicolumn{3}{|c|}{ PNM Rate } & \multirow{2}{*}{$\begin{array}{l}\text { ITRi- } \\
\text { GBD } \\
\text { rate }\end{array}$} & \multicolumn{3}{|c|}{ PNM Rate } & \multirow{2}{*}{$\begin{array}{l}\text { ITRi- } \\
\text { GBD } \\
\text { rate }\end{array}$} & \multicolumn{3}{|c|}{ PNM Rate } & \multirow{2}{*}{$\begin{array}{l}\text { ITRi- } \\
\text { GBD } \\
\text { rate }\end{array}$} \\
\hline & & SC & CBA & CBAR & & SC & CBA & CBAR & & SC & CBA & CBAR & \\
\hline \multirow{12}{*}{ Central-west } & 2005 & 33.01 & 37.7 & 28.14 & 46.81 & 116.8 & 133.41 & 98.08 & 119.96 & 770.57 & 870.85 & 664.45 & 628.05 \\
\hline & 2006 & 39.14 & 44.16 & 33.42 & 46.5 & 121.69 & 137.31 & 103.46 & 121.7 & 772.64 & 880.82 & 695.25 & 638.5 \\
\hline & 2007 & 43.02 & 48.16 & 36.89 & 46.59 & 135.9 & 152.15 & 116.86 & 123.69 & 879.11 & 968.11 & 780.15 & 655.26 \\
\hline & 2008 & 41.92 & 45.26 & 29.62 & 46.37 & 137.42 & 148.37 & 112.63 & 125.48 & 895.67 & 982.75 & 784.57 & 668.26 \\
\hline & 2009 & 41.05 & 46.51 & 40.35 & 45.78 & 135.79 & 153.83 & 124.33 & 127.12 & 865.73 & 963.57 & 762.27 & 683.57 \\
\hline & 2010 & 45.85 & 49.4 & 39.71 & 45.73 & 161.65 & 174.18 & 137.17 & 128.8 & 1021.7 & 1091.26 & 966.11 & 704.93 \\
\hline & 2011 & 39.77 & 42.78 & 38.57 & 45.59 & 162.88 & 175.22 & 142.7 & 129.02 & 1122.03 & 1220.4 & 1017.97 & 717.87 \\
\hline & 2012 & 42.19 & 45.31 & 34.51 & 45.34 & 156.37 & 167.94 & 141.24 & 129.15 & 1133.98 & 1204.87 & 1036.82 & 726.11 \\
\hline & 2013 & 47.25 & 51.27 & 38.98 & 45.27 & 157.18 & 170.53 & 134.75 & 128.85 & 1134 & 1239.34 & 1013.66 & 730.89 \\
\hline & 2014 & 50.76 & 53.88 & 43.58 & 45.72 & 172.05 & 182.62 & 150.02 & 130.9 & 1168.08 & 1241.34 & 1051.15 & 740.26 \\
\hline & 2015 & 48.54 & 51.14 & 41.57 & 45.69 & 175.99 & 185.4 & 153.07 & 132.04 & 1202.72 & 1269.38 & 1077.88 & 747.3 \\
\hline & 2016 & 52.7 & 55.09 & 45 & 45.24 & 155.4 & 162.46 & 134.75 & 130.41 & 1082.08 & 1134.15 & 965.35 & 747.68 \\
\hline \multirow{12}{*}{ Northeast } & 2005 & 15.08 & 21.71 & 8.64 & 36.38 & 50.12 & 72.18 & 44.01 & 89.53 & 329.23 & 526.64 & 311.05 & 464.24 \\
\hline & 2006 & 20.66 & 26.28 & 14.42 & 36.75 & 60.77 & 77.31 & 52.14 & 90.69 & 404.17 & 538.1 & 369.37 & 474.52 \\
\hline & 2007 & 20.8 & 26.05 & 16.55 & 37.34 & 65.15 & 81.59 & 58.27 & 92.14 & 453.49 & 580.12 & 428.57 & 485.36 \\
\hline & 2008 & 22.64 & 27.38 & 19.92 & 38.05 & 67.76 & 81.96 & 61.63 & 93.77 & 496.8 & 620.41 & 494.91 & 498.75 \\
\hline & 2009 & 25.73 & 30.97 & 21.47 & 38.4 & 81.91 & 98.57 & 74.83 & 96.44 & 580.07 & 714.57 & 562.65 & 516.74 \\
\hline & 2010 & 26.42 & 32.16 & 25.12 & 39.82 & 82.01 & 99.84 & 77.09 & 99.49 & 582.2 & 735.54 & 578.43 & 537.83 \\
\hline & 2011 & 31.02 & 35.5 & 27.03 & 40.92 & 97.21 & 111.26 & 86.26 & 102.59 & 689.71 & 802.52 & 665.46 & 560.42 \\
\hline & 2012 & 35.02 & 41.48 & 33.25 & 41.62 & 94.23 & 111.61 & 89.09 & 104.42 & 711.47 & 873.28 & 722.51 & 574.65 \\
\hline & 2013 & 35.75 & 41.38 & 34.11 & 41.89 & 111.8 & 129.39 & 104.64 & 104.84 & 866.46 & 1017.85 & 864.49 & 591.09 \\
\hline & 2014 & 33.93 & 37.25 & 30.82 & 42.27 & 107.22 & 117.69 & 95.34 & 104.89 & 863.34 & 944.77 & 801.32 & 599.36 \\
\hline & 2015 & 44.71 & 47.88 & 40.11 & 42.35 & 133.06 & 142.52 & 116.22 & 105.31 & 1064.49 & 1125.37 & 960.75 & 602.8 \\
\hline & 2016 & 41.27 & 43.1 & 36.48 & 41.49 & 142.29 & 148.6 & 121.87 & 103.41 & 1077.64 & 1099.25 & 943.64 & 589.09 \\
\hline \multirow{12}{*}{ North } & 2005 & 26.59 & 40.17 & 17.86 & 47.55 & 96.24 & 145.4 & 90.5 & 117.35 & 609.01 & 993.66 & 539.89 & 611.67 \\
\hline & 2006 & 27.41 & 39.83 & 21.49 & 48.05 & 91.16 & 132.46 & 90.95 & 119.44 & 565.69 & 871.81 & 552 & 626.32 \\
\hline & 2007 & 39.98 & 55.75 & 34.17 & 48.55 & 112.02 & 156.22 & 113.63 & 121.63 & 693.21 & 1012.57 & 702.07 & 637.22 \\
\hline & 2008 & 37.15 & 50.1 & 34.34 & 49.33 & 99.12 & 133.67 & 108.97 & 122.99 & 682.41 & 972.62 & 759.61 & 646.58 \\
\hline & 2009 & 31.2 & 41.73 & 32.07 & 48.9 & 107.38 & 143.61 & 106.84 & 125.2 & 735.57 & 1017.65 & 751.3 & 656.92 \\
\hline & 2010 & 41.3 & 55.72 & 41.15 & 50.06 & 113.9 & 153.68 & 113.73 & 127.63 & 667.43 & 959.87 & 769.91 & 666.56 \\
\hline & 2011 & 34.94 & 44.25 & 32.52 & 50.51 & 107.46 & 136.12 & 111.99 & 129.19 & 771.82 & 1020.56 & 786.33 & 680.53 \\
\hline & 2012 & 41.27 & 51.66 & 40.65 & 50.39 & 146.94 & 183.94 & 150.06 & 128.77 & 896.91 & 1192.07 & 1008.21 & 683.37 \\
\hline & 2013 & 40.97 & 50.91 & 45.35 & 50.41 & 134.38 & 166.98 & 139.06 & 129.65 & 901.3 & 1166.73 & 997.42 & 699.2 \\
\hline & 2014 & 47.56 & 56.58 & 48.87 & 50.36 & 143.1 & 170.23 & 141.27 & 131.74 & 988.09 & 1223.02 & 1047.64 & 709.97 \\
\hline & 2015 & 48.34 & 55.95 & 49.37 & 49.96 & 152.95 & 177.01 & 147.96 & 131.8 & 1119.29 & 1343.47 & 1164.32 & 714.14 \\
\hline & 2016 & 44.99 & 50.62 & 45.5 & 48.69 & 152.58 & 171.67 & 144.37 & 127.64 & 1055.21 & 1227.01 & 1074.09 & 697.73 \\
\hline \multirow{2}{*}{ Southeast } & 2005 & 40.74 & 46.73 & 34.05 & 62.6 & 138.27 & 158.62 & 118.76 & 167.43 & 912.29 & 1052.35 & 819.19 & 900.4 \\
\hline & 2006 & 49.3 & 54.16 & 40.78 & 63 & 162.29 & 178.29 & 137.48 & 170.56 & 1080.06 & 1201.48 & 964.69 & 917.72 \\
\hline
\end{tabular}




\begin{tabular}{|c|c|c|c|c|c|c|c|c|c|c|c|c|c|}
\hline & 2007 & 49.63 & 55.52 & 42.87 & 63.18 & 165.02 & 184.58 & 145.85 & 171.62 & 1065.77 & 1191.38 & 979.35 & 920.16 \\
\hline & 2008 & 49.53 & 54.7 & 43.03 & 63.71 & 163.13 & 180.15 & 144.3 & 173.35 & 1037.05 & 1151.15 & 960.65 & 928.84 \\
\hline & 2009 & 52.72 & 58.64 & 46.68 & 63.83 & 172.93 & 192.37 & 158.77 & 175.46 & 1090.4 & 1223.09 & 1041.38 & 947.17 \\
\hline & 2010 & 53.69 & 58.05 & 47.15 & 63.71 & 184.84 & 199.85 & 165.67 & 175 & 1180.72 & 1277.96 & 1096.43 & 965.61 \\
\hline & 2011 & 56.57 & 60.93 & 50.02 & 64 & 181.75 & 195.74 & 166.99 & 173.51 & 1197.06 & 1296.05 & 1130.62 & 974.37 \\
\hline & 2012 & 55.56 & 60.68 & 50.48 & 63.63 & 181.98 & 198.75 & 169.32 & 171.87 & 1193.92 & 1314.71 & 1158.07 & 974.93 \\
\hline & 2013 & 59.71 & 64.35 & 53.27 & 64.02 & 191.68 & 206.56 & 177.66 & 172.35 & 1219.32 & 1333.52 & 1173.3 & 991.78 \\
\hline & 2014 & 59.6 & 63.61 & 53.35 & 63.64 & 192.27 & 205.22 & 178.63 & 169.76 & 1268.99 & 1367.26 & 1215.97 & 998.68 \\
\hline & 2015 & 59.85 & 63.48 & 53.56 & 63.44 & 194.1 & 205.87 & 180.66 & 168.18 & 1326.77 & 1421.31 & 1271.32 & 1012.44 \\
\hline & 2016 & 67.13 & 70.75 & 60.01 & 62.81 & 198.4 & 209.09 & 184.85 & 164.07 & 1301.85 & 1386.56 & 1246.55 & 1039.62 \\
\hline \multirow{12}{*}{ South } & 2005 & 26.19 & 28.23 & 18.25 & 40.73 & 91.44 & 98.58 & 69.52 & 110.4 & 662.09 & 727.85 & 498.73 & 588.41 \\
\hline & 2006 & 32.5 & 34.63 & 23.38 & 40.99 & 107.23 & 114.23 & 83.64 & 112.4 & 701.48 & 771.55 & 564.93 & 597.63 \\
\hline & 2007 & 32.35 & 33.67 & 23.57 & 41.37 & 112.74 & 117.31 & 88.4 & 114.69 & 722.26 & 763.16 & 583.08 & 610.6 \\
\hline & 2008 & 32.91 & 35.1 & 25.01 & 41.32 & 104.46 & 111.39 & 84.83 & 115.41 & 681.23 & 748.75 & 581.7 & 617.59 \\
\hline & 2009 & 34.25 & 35.97 & 26.2 & 41.04 & 120.33 & 126.38 & 100.2 & 116.7 & 765.49 & 819.22 & 662.24 & 630.83 \\
\hline & 2010 & 34.4 & 36.19 & 28.8 & 40.91 & 123.34 & 129.74 & 104.49 & 117.05 & 820.15 & 873.3 & 720.57 & 647.1 \\
\hline & 2011 & 34.7 & 35.34 & 26.53 & 40.82 & 130.44 & 132.84 & 106.07 & 116.66 & 903.4 & 922.98 & 753.71 & 656.7 \\
\hline & 2012 & 32.27 & 34.17 & 27.57 & 40.47 & 125.43 & 132.79 & 108.35 & 115.79 & 790 & 867.28 & 748.69 & 659.59 \\
\hline & 2013 & 35.5 & 36.24 & 28.46 & 40.34 & 136.92 & 139.77 & 115.38 & 115.52 & 927.47 & 956.52 & 796.95 & 671.37 \\
\hline & 2014 & 39.28 & 40.24 & 32.57 & 40.52 & 135.95 & 139.27 & 115.69 & 115.65 & 915.92 & 951.94 & 810.95 & 681.79 \\
\hline & 2015 & 37.19 & 37.91 & 31.07 & 40.39 & 132.49 & 135.04 & 112.98 & 114.88 & 936.33 & 967.19 & 829.24 & 688.18 \\
\hline & 2016 & 47.08 & 47.75 & 39.58 & 40.42 & 138.85 & 140.82 & 118.57 & 113.83 & 996.5 & 1022.99 & 881.96 & 708.89 \\
\hline
\end{tabular}

Note: PNM-SC rate: Pneumonia rate without correction; PNM-CBA rate: Pneumonia rate corrected by the active search survey; PNM-CBAR rate: Pneumonia rate corrected by research on active search and reassignment; ITRi-GBD Rate: Global Burden Disease infection rate of the lower respiratory tract.

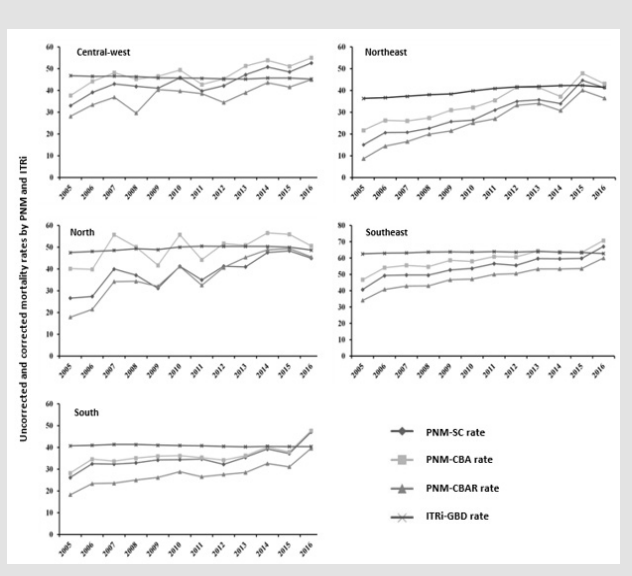

Figure 2: Trend of rates (per 100,000) uncorrected and corrected for mortality from pneumonia and lower respiratory tract infection in elderly aged 60 to 64 years by region. Brazil, 2005 - 2016.

Note: PNM-SC rate: Pneumonia rate without correction; PNM-CBA rate: Pneumonia rate corrected by the active search survey; PNM-CBAR rate: Pneumonia rate corrected by research on active search and reassignment; ITRi-GBD Rate: Global Burden Disease infection rate of the lower respiratory tract. 


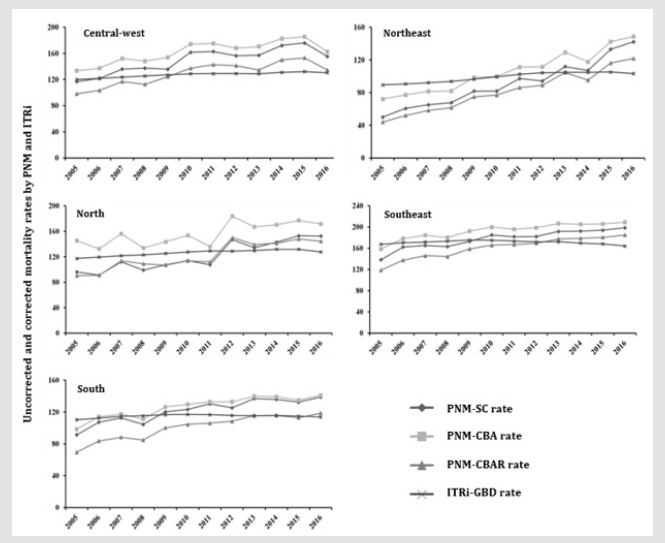

Figure 3: Trend of rates (per 100,000) uncorrected and corrected for mortality from pneumonia and lower respiratory tract infection in elderly aged 65 to 79 years by region. Brazil, 2005 - 2016.

Note: PNM-SC rate: Pneumonia rate without correction; PNM-CBA rate: Pneumonia rate corrected by the active search survey; PNM-CBAR rate: Pneumonia rate corrected by research on active search and reassignment; ITRi-GBD Rate: Global Burden Disease infection rate of the lower respiratory tract.

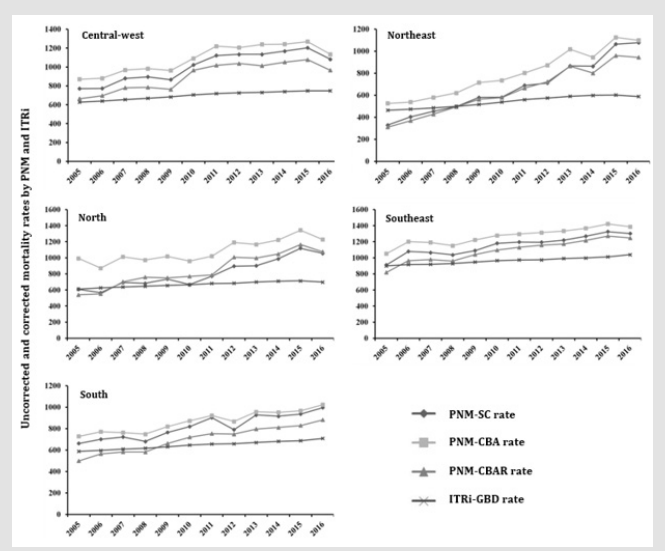

Figure 4: Trend of rates (per 100,000) uncorrected and corrected for mortality from pneumonia and lower respiratory tract infection in elderly aged 80 years or older by region. Brazil, 2005 - 2016.

Note: PNM-SC rate: Pneumonia rate without correction; PNM-CBA rate: Pneumonia rate corrected by the active search survey; PNM-CBAR rate: Pneumonia rate corrected by research on active search and reassignment; ITRi-GBD Rate: Global Burden Disease infection rate of the lower respiratory tract.

Table 2: Number of deaths without correction and corrected by pneumonia and ITRi by GBD by age group of elderly, region and year. Brazil, 2005-2016.

\begin{tabular}{|c|c|c|c|c|c|c|c|c|c|c|c|c|c|}
\hline \multirow{4}{*}{ Region } & \multirow{4}{*}{ Year } & \multicolumn{12}{|c|}{ Age group (years) } \\
\hline & & \multicolumn{4}{|c|}{$60-64$} & \multicolumn{4}{|c|}{ 65-79 } & \multicolumn{4}{|c|}{$\geq 80$} \\
\hline & & \multicolumn{3}{|c|}{ Deaths PNM } & \multirow{2}{*}{$\begin{array}{c}\text { Deaths } \\
\text { ITRi- } \\
\text { GBD }\end{array}$} & \multicolumn{3}{|c|}{ Deaths PNM } & \multirow{2}{*}{$\begin{array}{l}\text { Deaths } \\
\text { ITRi- } \\
\text { GBD }\end{array}$} & \multicolumn{3}{|c|}{ Deaths PNM } & \multirow{2}{*}{$\begin{array}{c}\text { Deaths } \\
\text { ITRi- } \\
\text { GBD }\end{array}$} \\
\hline & & SC & CBA & CBAR & & SC & CBA & CBAR & & SC & CBA & CBAR & \\
\hline \multirow{6}{*}{$\begin{array}{c}\text { Central- } \\
\text { west }\end{array}$} & 2005 & 104 & 119 & 89 & 147 & 600 & 685 & 504 & 616 & 774 & 875 & 667 & 631 \\
\hline & 2006 & 129 & 146 & 110 & 153 & 653 & 737 & 555 & 653 & 816 & 930 & 734 & 674 \\
\hline & 2007 & 149 & 167 & 128 & 161 & 761 & 852 & 654 & 693 & 980 & 1,079 & 870 & 730 \\
\hline & 2008 & 153 & 165 & 108 & 169 & 803 & 867 & 658 & 733 & 1,056 & 1,159 & 925 & 788 \\
\hline & 2009 & 158 & 179 & 155 & 176 & 829 & 939 & 759 & 776 & 1,080 & 1,202 & 951 & 853 \\
\hline & 2010 & 186 & 200 & 161 & 186 & 1,033 & 1,113 & 877 & 823 & 1,348 & 1,440 & 1,275 & 930 \\
\hline
\end{tabular}




\begin{tabular}{|c|c|c|c|c|c|c|c|c|c|c|c|c|c|}
\hline & 2011 & 170 & 183 & 165 & 195 & 1,091 & 1,174 & 956 & 864 & 1,566 & 1,703 & 1,421 & 1,002 \\
\hline & 2012 & 190 & 204 & 155 & 204 & 1,099 & 1,180 & 993 & 908 & 1,675 & 1,780 & 1,531 & 1,073 \\
\hline & 2013 & 224 & 243 & 185 & 215 & 1,160 & 1,259 & 994 & 951 & 1,774 & 1,939 & 1,586 & 1,143 \\
\hline & 2014 & 253 & 269 & 217 & 228 & 1,334 & 1,416 & 1,163 & 1,015 & 1,938 & 2,060 & 1,744 & 1,228 \\
\hline & 2015 & 254 & 268 & 218 & 239 & 1,434 & 1,511 & 1,247 & 1,076 & 2,119 & 2,236 & 1,899 & 1,317 \\
\hline & 2016 & 289 & 302 & 247 & 248 & 1,331 & 1,391 & 1,154 & 1,117 & 2,027 & 2,125 & 1,808 & 1,401 \\
\hline \multirow{12}{*}{ Northeast } & 2005 & 197 & 284 & 113 & 475 & 1,206 & 1,737 & 1,059 & 2,154 & 2,042 & 3,266 & 1,929 & 2,879 \\
\hline & 2006 & 278 & 354 & 194 & 494 & 1,495 & 1,902 & 1,282 & 2,231 & 2,569 & 3,420 & 2,348 & 3,016 \\
\hline & 2007 & 290 & 363 & 231 & 521 & 1,637 & 2,050 & 1,464 & 2,315 & 2,965 & 3,793 & 2,802 & 3,173 \\
\hline & 2008 & 328 & 397 & 289 & 551 & 1,740 & 2,105 & 1,583 & 2,408 & 3,345 & 4,177 & 3,332 & 3,358 \\
\hline & 2009 & 387 & 466 & 323 & 577 & 2,155 & 2,593 & 1,969 & 2,537 & 4,016 & 4,947 & 3,895 & 3,578 \\
\hline & 2010 & 411 & 500 & 391 & 619 & 2,218 & 2,700 & 2,085 & 2,691 & 4,134 & 5,223 & 4,107 & 3,819 \\
\hline & 2011 & 498 & 570 & 434 & 657 & 2,710 & 3,101 & 2,405 & 2,860 & 5,016 & 5,836 & 4,840 & 4,076 \\
\hline & 2012 & 579 & 686 & 550 & 688 & 2,714 & 3,215 & 2,566 & 3,008 & 5,294 & 6,498 & 5,376 & 4,276 \\
\hline & 2013 & 608 & 704 & 580 & 712 & 3,331 & 3,855 & 3,118 & 3,123 & 6,603 & 7,757 & 6,588 & 4,505 \\
\hline & 2014 & 594 & 652 & 540 & 740 & 3,303 & 3,626 & 2,937 & 3,231 & 6,764 & 7,402 & 6,278 & 4,696 \\
\hline & 2015 & 807 & 864 & 724 & 764 & 4,234 & 4,535 & 3,698 & 3,351 & 8,616 & 9,109 & 7,776 & 4,879 \\
\hline & 2016 & 769 & 803 & 680 & 773 & 4,673 & 4,880 & 4,002 & 3,396 & 9,049 & 9,230 & 7,924 & 4,947 \\
\hline \multirow{12}{*}{ North } & 2005 & 73 & 110 & 49 & 131 & 428 & 647 & 402 & 522 & 531 & 866 & 471 & 533 \\
\hline & 2006 & 78 & 113 & 61 & 137 & 420 & 610 & 419 & 550 & 510 & 786 & 498 & 565 \\
\hline & 2007 & 118 & 165 & 101 & 143 & 535 & 746 & 543 & 581 & 650 & 949 & 658 & 598 \\
\hline & 2008 & 114 & 154 & 105 & 151 & 491 & 662 & 540 & 609 & 668 & 952 & 744 & 633 \\
\hline & 2009 & 100 & 134 & 103 & 157 & 552 & 738 & 549 & 644 & 753 & 1,042 & 769 & 672 \\
\hline & 2010 & 139 & 188 & 139 & 168 & 608 & 820 & 607 & 681 & 715 & 1,028 & 825 & 714 \\
\hline & 2011 & 124 & 157 & 115 & 179 & 596 & 755 & 621 & 717 & 866 & 1,145 & 882 & 764 \\
\hline & 2012 & 155 & 194 & 153 & 189 & 847 & 1,060 & 865 & 742 & 1,055 & 1,402 & 1,186 & 804 \\
\hline & 2013 & 163 & 203 & 180 & 201 & 806 & 1,002 & 834 & 778 & 1,112 & 1,439 & 1,231 & 863 \\
\hline & 2014 & 200 & 238 & 206 & 212 & 895 & 1,065 & 884 & 824 & 1,279 & 1,583 & 1,356 & 919 \\
\hline & 2015 & 214 & 248 & 219 & 221 & 1,000 & 1,157 & 967 & 862 & 1,520 & 1,824 & 1,581 & 970 \\
\hline & 2016 & 209 & 235 & 211 & 226 & 1,045 & 1,176 & 989 & 874 & 1,504 & 1,749 & 1,531 & 994 \\
\hline \multirow{12}{*}{ Southeast } & 2005 & 949 & 1,089 & 793 & 1,458 & 5,985 & 6,866 & 5,140 & 7,247 & 9,019 & 10,404 & 8,099 & 8,902 \\
\hline & 2006 & 1,199 & 1,317 & 992 & 1,532 & 7,205 & 7,915 & 6,103 & 7,572 & 11,288 & 12,557 & 10,082 & 9,591 \\
\hline & 2007 & 1,269 & 1,419 & 1,096 & 1,615 & 7,505 & 8,395 & 6,633 & 7,806 & 11,807 & 13,199 & 10,850 & 10,194 \\
\hline & 2008 & 1,336 & 1,475 & 1,161 & 1,718 & 7,605 & 8,398 & 6,727 & 8,082 & 12,176 & 13,516 & 11,279 & 10,905 \\
\hline & 2009 & 1,499 & 1,668 & 1,327 & 1,815 & 8,287 & 9,219 & 7,609 & 8,408 & 13,529 & 15,175 & 12,921 & 11,752 \\
\hline & 2010 & 1,605 & 1,735 & 1,410 & 1,905 & 9,141 & 9,883 & 8,193 & 8,654 & 15,419 & 16,689 & 14,318 & 12,610 \\
\hline & 2011 & 1,774 & 1,911 & 1,569 & 2,007 & 9,307 & 10,023 & 8,551 & 8,885 & 16,409 & 17,766 & 15,498 & 13,356 \\
\hline & 2012 & 1,823 & 1,991 & 1,656 & 2,088 & 9,679 & 10,571 & 9,006 & 9,141 & 17,146 & 18,881 & 16,631 & 14,001 \\
\hline & 2013 & 2,046 & 2,205 & 1,825 & 2,194 & 10,616 & 11,440 & 9,839 & 9,545 & 18,318 & 20,034 & 17,627 & 14,900 \\
\hline & 2014 & 2,129 & 2,272 & 1,906 & 2,274 & 11,106 & 11,854 & 10,318 & 9,806 & 19,928 & 21,471 & 19,095 & 15,683 \\
\hline & 2015 & 2,226 & 2,361 & 1,992 & 2,359 & 11,706 & 12,416 & 10,896 & 10,142 & 21,770 & 23,321 & 20,860 & 16,612 \\
\hline & 2016 & 2,595 & 2,735 & 2,320 & 2,428 & 12,503 & 13,177 & 11,649 & 10,340 & 22,319 & 23,771 & 21,371 & 17,823 \\
\hline \multirow{6}{*}{ South } & 2005 & 221 & 238 & 154 & 344 & 1,365 & 1,472 & 1,038 & 1,648 & 2,093 & 2,301 & 1,577 & 1,860 \\
\hline & 2006 & 286 & 305 & 206 & 361 & 1,650 & 1,758 & 1,287 & 1,730 & 2,349 & 2,584 & 1,892 & 2,001 \\
\hline & 2007 & 298 & 310 & 217 & 381 & 1,788 & 1,861 & 1,402 & 1,819 & 2,568 & 2,713 & 2,073 & 2,171 \\
\hline & 2008 & 318 & 339 & 242 & 399 & 1,709 & 1,822 & 1,388 & 1,888 & 2,572 & 2,827 & 2,196 & 2,332 \\
\hline & 2009 & 347 & 364 & 265 & 416 & 2,035 & 2,137 & 1,695 & 1,974 & 3,063 & 3,278 & 2,650 & 2,524 \\
\hline & 2010 & 365 & 384 & 306 & 434 & 2,162 & 2,274 & 1,831 & 2,052 & 3,468 & 3,693 & 3,047 & 2,736 \\
\hline
\end{tabular}




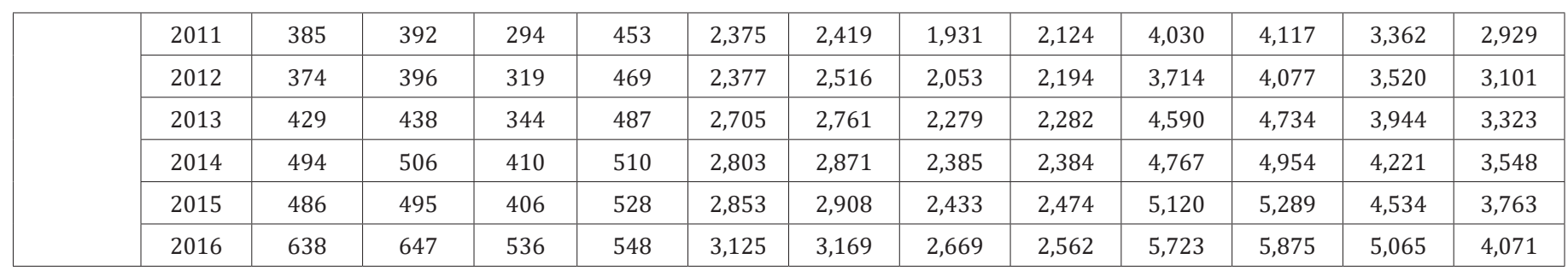

Note: Deaths PNM-SC: Number of deaths from pneumonia without correction; Deaths PNM-CBA: Number of deaths from pneumonia corrected by the search for active search; Deaths PNM-CBAR: Number of deaths from pneumonia corrected by the search for active search and redistribution; Deaths ITRi-GBD: Number of deaths due to infection of the lower respiratory tract by Global Burden Disease.

Table 3: Adjustments of the linear regression model for annual rates (per 100.000) without correction and corrected for mortality from pneumonia and ITRi by GBD by age group. region and year. Brazil. 2005-2016.

\begin{tabular}{|c|c|c|c|c|c|c|c|c|c|c|c|c|c|}
\hline \multirow{3}{*}{ Region } & \multirow{3}{*}{ Rate } & \multicolumn{12}{|c|}{ Age Group (Years) } \\
\hline & & \multicolumn{4}{|c|}{$60-64$} & \multicolumn{4}{|c|}{$65-79$} & \multicolumn{4}{|c|}{$\geq 80$} \\
\hline & & B0 & B1 & R2 & p-value & В0 & B1 & R2 & p-value & В0 & B1 & R2 & p-value \\
\hline \multirow{4}{*}{$\begin{array}{l}\text { Central- } \\
\text { West }\end{array}$} & PNM-SC & $-2,623.28$ & 1.33 & 0.75 & 0.00 & $-9,187.18$ & 4.64 & 0.76 & 0.00 & $-79,253.11$ & 39.92 & 0.83 & 0.00 \\
\hline & PNM-CBA & $-2,159.01$ & 1.1 & 0.64 & 0.00 & $-7,710.01$ & 3.92 & 0.69 & 0.00 & $-72,315.14$ & 36.51 & 0.78 & 0.00 \\
\hline & PNM-CBAR & $-2,309.90$ & 1.17 & 0.65 & 0.00 & $-8,649.69$ & 4.37 & 0.77 & 0.00 & $-74,116.02$ & 37.31 & 0.79 & 0.00 \\
\hline & ITRi - GBD & 310.21 & -0.13 & 0.76 & 0.00 & $-1,852.30$ & 0.99 & 0.88 & 0.00 & $-22,808.20$ & 11.69 & 0.96 & 0.00 \\
\hline \multirow{4}{*}{ Northeast } & PNM-SC & $-4,852.43$ & 2.43 & 0.94 & 0.00 & $-15,594.48$ & 7.8 & 0.96 & 0.00 & $-135,659.48$ & 67.81 & 0.97 & 0.00 \\
\hline & PNM-CBA & $-4,274.03$ & 2.14 & 0.9 & 0.00 & $-13,727.79$ & 6.88 & 0.95 & 0.00 & $-116,366.77$ & 58.28 & 0.96 & 0.00 \\
\hline & PNM-CBAR & $-5,214.50$ & 2.61 & 0.94 & 0.00 & $-13,694.46$ & 6.85 & 0.97 & 0.00 & $-121,006.05$ & 60.51 & 0.98 & 0.00 \\
\hline & ITRi - GBD & $-1,162.76$ & 0.6 & 0.91 & 0.00 & $-3,106.01$ & 1.59 & 0.89 & 0.00 & $-27,463.68$ & 13.93 & 0.95 & 0.00 \\
\hline \multirow{4}{*}{ North } & PNM-SC & $-3,883.61$ & 1.7 & 0.72 & 0.00 & $-11,702.45$ & 5.88 & 0.85 & 0.00 & $-95,061.13$ & 47.68 & 0.9 & 0.00 \\
\hline & PNM-CBA & $-1,916.00$ & 1.01 & 0.33 & 0.05 & $-7,281.50$ & 3.7 & 0.56 & 0.01 & $-68,085.54$ & 34.4 & 0.77 & 0.00 \\
\hline & PNM-CBAR & $-5,094.72$ & 2.55 & 0.82 & 0.00 & $-10,968.65$ & 5.52 & 0.83 & 0.00 & $-110,098.37$ & 55.18 & 0.93 & 0.00 \\
\hline & ITRi - GBD & -321.55 & 0.19 & 0.42 & 0.02 & $-2,269.11$ & 1.09 & 0.81 & 0.00 & $-17,626.69$ & 9.1 & 0.94 & 0.00 \\
\hline \multirow{4}{*}{ Southeast } & PNM-SC & $-3,582.01$ & 1.81 & 0.91 & 0.00 & $-8,998.49$ & 4.56 & 0.88 & 0.00 & $-63,280.46$ & 32.05 & 0.9 & 0.00 \\
\hline & PNM-CBA & $-3,187.69$ & 1.62 & 0.89 & 0.00 & $-7,504.34$ & 3.83 & 0.85 & 0.00 & $-55,608.15$ & 28.29 & 0.9 & 0.00 \\
\hline & PNM-CBAR & $-3,743.50$ & 1.89 & 0.94 & 0.00 & $-10,699.39$ & 5.4 & 0.92 & 0.00 & $-73,777.58$ & 36.94 & 0.94 & 0.00 \\
\hline & ITRi - GBD & -12.46 & 0.04 & 0.09 & 0.36 & 795.13 & -0.31 & 0.11 & 0.28 & $-22,516.79$ & 11.68 & 0.98 & 0.00 \\
\hline \multirow{4}{*}{ South } & PNM-SC & $-2,269.58$ & 1.45 & 0.69 & 0.00 & $-7,582.81$ & 3.83 & 0.86 & 0.00 & $-59,185.15$ & 29.85 & 0.88 & 0.00 \\
\hline & PNM-CBA & $-1,999.85$ & 1.01 & 0.64 & 0.00 & $-6,689.99$ & 3.39 & 0.84 & 0.00 & $-52,288.98$ & 26.44 & 0.92 & 0.00 \\
\hline & PNM-CBAR & $-2,686.32$ & 1.35 & 0.83 & 0.00 & $-8,147.99$ & 4.1 & 0.9 & 0.00 & $-66,488.22$ & 33.42 & 0.97 & 0.00 \\
\hline & ITRi - GBD & 192.01 & -0.08 & 0.57 & 0.00 & -336.72 & 0.23 & 0.18 & 0.17 & $-20,466.51$ & 10.5 & 0.99 & 0.00 \\
\hline
\end{tabular}

Note: PNM-SC rate. Pneumonia rate without correction; PNM-CBA rate. Pneumonia rate corrected by the active search survey; PNM-CBAR Rate. Pneumonia rate corrected by the search for active search and redistribution; ITRi-GBD Rate. Global Burden Disease infection rate of the lower respiratory tract

\section{Discussion}

The main results of this study were

a) Estimation of mortality rates due to PNM, using correction methods for underreporting deaths [8] and the basic cause of death [10]; and

b) The analysis of the trend in mortality rates due to PNM in the elderly by regions and age group.

There was a progressive increase in mortality rates due to PNM in elderly people in Brazil directly proportional to age; it was also possible to describe the differences between the geographic regions of the country.

Brazil is a country of continental dimensions and important social and economic differences in each region $[18,19]$. In this study, the Northeast region, followed by the North, were those that showed the highest increase in the mortality rate due to CBAR pneumonia in all age groups. In this sense, research has shown that these two regions present disparities in the indicators of education, material deprivation and use of health services when compared to the others [19]. Recent national research on the trend 
of mortality due to PNM in Brazil also lists the Northeast and North regions as being disparate in relation to the others [20]. There is no doubt that the increase in investment in public policies aimed at vaccination is associated with the relevant reduction in general and specific mortality due to PNM and influenza, as well as the reduction of health inequities in the country [21]. An important result of this study was the identification of a tendency to increase the magnitude of mortality rates due to PNM in elderly people in Brazil in all regions of the country, in the period from 2005 to 2016

This increase in mortality was directly proportional to the increase in the age group of the elderly. Studies have shown an increasing trend both in mortality [20] and in morbidity due to PNM in the elderly in Brazil, even after the implementation of intervention strategies [22]. With advancing age, in addition to increasing exposure to environmental factors, the body's defense mechanisms reduce the ability to fight pathogenic microorganisms, increasing susceptibility to communicable diseases (immunosensitivity or immune aging), which is aggravated by the multicomorbidities present in this age group [6,7,23-25]. Such an assertion may be associated with the increase in mortality rates in elderly people aged 80 years or older observed in this research. This increase is in contrast to what has been observed in other countries that implanted conjugated pneumococcal vaccination for children longer than in Brazil, in addition to having also implemented it for adults $[23,26,27]$. Although in these countries the number of deaths due to ITRi in the elderly is higher than in other age groups, mortality rates have been decreasing.

The main speculation is that it is associated with the effect of herd immunization and also with vaccination in the elderly themselves $[23,26]$. Until the completion of this study, the 23 -valent polysaccharide vaccine was available only in private clinics, with limited access to the elderly with greater purchasing power. The vaccine is only available free of charge for special groups of hospitalized elderly and/or residents of long-term care facilities, as well as for people with chronic and immunodepressed diseases [28]. There is a need to direct efforts to increase the availability of the vaccine to all the elderly in the country. Despite the important improvement in the coverage and quality of the information contained in the SIM $[2,3,29]$, there are still regional inequalities in terms of filling the causes of death in the DO, which makes it difficult to know the 'true' burden of PNM in the Brazil. In addition, it is important to emphasize errors in filling out and coding the causes of death in DO. These are observed, more frequently, in the elderly population due to the multiple comorbidities presented that make it difficult to define the real basic cause of death $[6,7,23]$.

Part of the deaths registered as PNM are, in fact, an associated cause or do not represent the basic cause of death [6,30,31]. A study carried out in 2010 in Brazil reclassified 65.5\% of ill-defined causes [3]. Another study redistributed $67 \%$ of the cases of neoplasms after applying linkage between databases [32]. In 2018, a study redistributed $17.4 \%$ of the cases in which PNM was considered a basic cause of death [10]. Still in that same study, after applying the strategy to redistribute the basic cause of death, the mortality rate due to PNM in Brazil reduced seven deaths per 100,000 inhabitants. In particular, the study presented here adopts CBAR strategies, correction of under enumeration and overestimation of deaths, as a more appropriate estimate of the burden of PNM in the elderly population for Brazil. The use of these two strategies allowed to know more robust estimates of mortality rates due to PNM in the elderly in Brazil, which contributed to the reduction of garbage codes.

The use of ITRi-GBD rates served as a parameter to compare two proposed correction methodologies: CBA and CBAR. Although a previous study showed an increase in both the number of deaths and mortality rates due to ITRi in the population aged 70 years or older [33], in this research the trend of ITRi-GBD rates showed a more stable behavior during the series when compared with CBAR rates. The correction factors used by the GBD methodology to project the rates appear to be much higher at the beginning when compared to the end. This fact can be seen in the improvement in the quality of SIM data in recent years $[2,3,29]$. There are several actions taken by the MS and by the state and municipal health secretariats, in partnership with universities, in order to reduce problems related to the coverage and inadequate filling of causes of death in DO, mainly errors of diagnosis of the basic cause of death [2,3,8,34]. An important action taken was the research named "Active Search for Deaths and Births" and the Project to Reduce Ill-Defined Causes of Death, which managed to reduce the under-registration of deaths and the percentage of causes of death codified in chapter XVIII of the ICD- $10[8,9]$.

The adoption of this strategy, CBA, has already been applied in other studies with the same purpose, which is to correct the underregistration and bring it closer to values closer to the real $[7,35]$. But in this study, we corrected in addition to the under-registration the coding errors of the basic cause. Another aspect that should be emphasized is the lesser protection of the herd conferred by infant 10 -valent pneumococcal vaccination in the extreme elderly, in addition to the low effectiveness of the vaccine for disease prevention in the elderly when compared to young adults. It is also important to highlight the increase in the circulation of non-vaccine serotypes in this population [36].

This study enabled estimates closer to the reality of mortality rates due to PNM in the elderly in the five regions of Brazil, since both the under-registration correction (CBA) was adopted, which in theory would increase the number of notifications, as well as errors codification through the redistribution of deaths by PNM to other causes. The main limitations of the study were the presence of a certain degree of uncertainty in the estimated rates, even after 
using the proposed methodology. The additional use of basic cause redistribution research may present limitations related to possible biases that may have occurred in the database linkage process, such as different patterns of cause of death between cases that were paired and not paired [10]. Despite the limitations listed when using data from the MS information systems, it is believed that the technique proposed in this study represents a viable and adequate alternative for estimating the mortality burden of PNM in the elderly. In addition, studies that include validation and reliability strategies for improving methodologies to correct information on the basic cause of death are necessary and should be encouraged to improve the SIM.

\section{Conclusion}

This study proposed and used methodologies to correct the mortality rate due to PNM in Brazil that can be applied in analyzes for other groups of causes. The results showed that in 2016 there were more risks of mortality from PNM in the Southeast and North regions; and that the trends of increase in mortality rates due to PNM in elderly people aged 60 years or older in Brazil, with higher rates of increases, were in the Northeast and North regions of the country. The magnitude and trend estimates presented in the study make it possible to analyze the behavior of mortality rates due to PNM in the elderly in Brazil. In addition, they can subsidize the National Immunization Program on the need to include a specific pneumococcal vaccine for the entire elderly population.

\section{Acknowledgement}

To the National Council for Scientific and Technological Development (CNPq), for granting a doctoral scholarship to the first author.

\section{Conflict of Interest}

The authors have declared that no competing interest exists.

\section{Author's Contribution}

DBM, ALA and OLMN worked on the conception and design of the research, the analysis and interpretation of data, the writing of the article and the approval of the version to be published. GMP, RM and ALB worked on data analysis and interpretation, writing the article and approving the version to be published.

\section{References}

1. Frias PG, Szwarcwald CL, Morais OL, Leal MC, Cortez Escalante JJ, et al. (2017) Use of vital data to estimate mortality indicators in Brazil: from the active search for events to the development of methods. Cad Saude Publica 33(3): e00206015.

2. Souza MFM, França EB, Cavalcante A (2017) Burden of disease and health situation analysis: results of the Global Burden of Disease (GBD) Brazil network. Rev Bras Epidemiol 1(Suppl 1): 1-3.
3. França E, Teixeira R, Ishitani L, Duncan BB, Cortez Escalante JJ, et al. (2014) Ill-defined causes of death in Brazil: a redistribution method based on the investigation of such causes. Rev. Saude Publica 48(4): 671-81.

4. Jorge MHPM, Cascão ÂM, Reis AC, Laurenti R (2012) In search of better information on the basic cause of death through linkage: a snapshot on external causes in the elderly - State of Rio de Janeiro, Brazil, 2006. Epidemiology and Health Services 21(3): 407-418.

5. Naghavi M, Makela S, Foreman K, O’Brien J, Pourmalek F, et al. (2010) Algorithms for enhancing public health utility of national causes-ofdeath data. Popul Health Metr 8: 9

6. Ishitani LH, Teixeira RA, Abreu DMX, Paixão LMMM, França EB (2017) Quality of mortality statistics' information: garbage codes as causesof death in Belo Horizonte, 2011-2013. Rev Bras Epidemiol 1(Suppl 1): 34 45 .

7. Jorge MHPDM, Laurenti R, Lima-Costa MF, Gotlieb SLD, Filho ADPC (2008) Elderly mortality in Brazil: the question of ill-defined causes. Epidemio. and Health Services 17(4): 271-281.

8. (2018) DATASUS. Health information. Correction and redistribution of deaths according to the active search survey. Ministry of Health of Brazil.

9. Szwarcwald CL, Neto OLM, Frias PG, Junior PRBS, Cortez JJE, et al (2011) Active search for deaths and births in the Northeast and the Legal Amazon: Estimation of SIM and Sinasc coverage in Brazilian municipalities. In: Ministry of Health of Brazil, Health Brazil 2010: an analysis of the health situation and selected evidence of the impact of health surveillance actions, Brasília p. 79-98.

10. Policena GM (2018) Redistribution of the underlying cause of deaths from pneumonia in adults by matching hospitalization and mortality records, Brazil, 2008-2013. Goiânia, Federal University of Goiás.

11. Cascão AM, Jorge MHPM, Costa AJL, Kale PL (2016) Use of primary diagnosis during hospitalization in the Unified Health System (Sistema Único de Saúde) to qualify information regarding the underlying cause of natural deaths among the elderly. Rev Bras Epidemiol 19(4): 713-726.

12. (2018) Brazilian Institute of Geography and Statistics of Brazil. Statistic. Brazilian census.

13. GBD 2015 Disease and Injury Incidence and Prevalence Collaborators (2016) Global, regional, and national incidence, prevalence, and years lived with disability for 310 diseases and injuries, 1990-2015: a systematic analysis for the Global Burden of Disease Study 2015. Lancet 388(10053): 1545-1602.

14. Murray CJL, Lopez AD (1996) The global burden of disease: a comprehensive assessment of mortality and disability from deceases, injuries and risk factors in 1990 and projected to 2010. Harvard Univ Press 1(1): 1-35.

15. (2018) Institute for Health Metrics and Evaluation. GBD Compare.

16. Latorre MRDO, Cardoso MRA (2001) Analysis of time series in epidemiology: an introduction to methodological aspects. Rev Bras Epidemiol 4(3): 145-152.

17. (2012) Ministry of Health of Brazil. National Health Council. Resolution no. 466 of December 12, 2012, Brasilia.

18. Vasconcelos AMN, Gomes MMF (2012) Demographic transition: the Brazilian experience. Epidemiol e Serviços Saúde 21(4): 539-548.

19. Szwarcwald CL, Souza PRB, Marques AP, Almeida WDS, Montilla DER (2016) Inequalities in healthy life expectancy by Brazilian geographic regions: findings from the National Health Survey, 2013. Int J Equity Health 15(1): 141.

20. Ferraz RO, Oliveira-Friestino JK, Francisco PMSB (2017) Pneumonia mortality trends in all Brazilian geographical regions between 1996 and 2012. J Bras Pneumol 43(4): 274-279. 
21. Antunes JLF, Waldman EA, Borrell C, Paiva TM (2007) Effectiveness of influenza vaccination and its impact on health inequalities. Int J Epidemiol 36(6): 1319-1326.

22. Andrade AL, Afonso ET, Minamisava R, Bierrenbach AL, Cristo EB, et al (2017) Direct and indirect impact of 10 -valent pneumococcal conjugate vaccine introduction on pneumonia hospitalizations and economic burden in all age-groups in Brazil: A time-series analysis. PLoS One 12(9): e0184204.

23. Lexau CA, Lynfield R, Danila R, Pilishvili T, Facklam R, et al. (2005) Changing epidemiology of invasive pneumococcal disease among older adults in the era of pediatric pneumococcal conjugate vaccine. JAMA 294(16): 2043-2051.

24. Almirall J, Serra Prat M, Bolibar I (2016) Risk Factors for Communityacquired Pneumonia in Adults: a review. Clin Pulm Med 23(3): 99-104.

25. Almirall J, Serra Prat M, Bolíbar I, Balasso V (2017) Risk Factors for Community-Acquired Pneumonia in Adults: A Systematic Review of Observational Studies. Respiration 94(3): 299-311.

26. Harboe ZB, Dalby T, Weinberger DM, Benfield T, Mølbak K, et al. (2014) Impact of 13-valent pneumococcal conjugate vaccination in invasive pneumococcal disease incidence and mortality. Clin Infect Dis 59(8): 1066-1073

27. Bonten MJM, Huijts SM, Bolkenbaas M, Webber C, Patterson S, et al. (2015) Polysaccharide conjugate vaccine against pneumococcal pneumonia in adults. N Engl J Med 372(12): 1114-1125.

28. (2014) Ministry of Health of Brazil. Manual of reference centers for special immunobiologists. Brasilia.

29. Phillips DE, Lozano R, Naghavi M, Atkinson C, Gonzalez Medina D, et al. (2014) A composite metric for assessing data on mortality and causes of death: the vital statistics performance index. Popul Health Metr 12: 14

\section{ISSN: 2574-1241}

DOI: $10.26717 / B J S T R .2020 .29 .004830$

Denismar Borges de Miranda. Biomed J Sci \& Tech Res

(C) This work is licensed under Creative

Submission Link: https://biomedres.us/submit-manuscript.php
30. Lozano R, Naghavi M, Foreman K, Lim S, Shibuya K, et al. (2012) Global and regional mortality from 235 causes of death for 20 age groups in 1990 and 2010: a systematic analysis for the Global Burden of Disease Study 2010. Lancet 380(9859): 2095-2128.

31. Sgambatti S, Minamisava R, Afonso ET, Toscano CM, Bierrenbach AL, et al. (2015) Appropriateness of administrative data for vaccine impact evaluation: the case of pneumonia hospitalizations and pneumococcal vaccine in Brazil. Epidemiol Infect 143(2): 334-342.

32. Oliveira PPV, Silva GA, Curado MP, Malta DC, Moura L (2014) Reliability of cancer as the underlying cause of death according to the Mortality Information System and Population-Based Cancer Registry in Goiânia, Goiás State, Brazil. Cad Saude Publica 30(2): 296-304.

33. Corrêa RA, José BPS, Malta DC, Passos VMA, França EB, et al (2017) Burden of disease by lower respiratory tract infections in Brazil, 1990 to 2015: estimates of the Global Burden of Disease 2015 study. Rev Bras Epidemiol 1(Suppl 01): 171-181.

34. Batista Filho M, Cruz RSBLC (2015) Children's health in the world and in Brazil. Rev Bras Maternal Health Infant 15(4): 451-54.

35. Almeida WS, Szwarcwald CL (2017) Adequacy of mortality data and correction of reported deaths from the Proactive Search of Deaths. Cien Saude Colet 22(10): 3193-3203.

36. Christophe BL, Mott M, Cunha G, Caierão J, Azevedo PD, et al. (2018) Characterisation of Streptococcus pneumoniae isolates from invasive disease in adults following the introduction of PCV10 in Brazil. J Med Microbiol 67(5): 687-694.

$\begin{array}{ll}\text { BIOMEDICAL } & \text { Assets of Publishing with us } \\ \text { RESEARCHES } & \text { - Global archiving of articles } \\ & \text { - Immediate, unrestricted online access } \\ & \text { - Rigorous Peer Review Process } \\ & \end{array}$

